\title{
Primary Adrenal Tumors-Five Years Single Centre Experience
}

\author{
Rashmi D. Patel*, Aruna V. Vanikar, Kamlesh S. Suthar, Kamal V. Kanodia \\ Department of Pathology, Laboratory Medicine and Transfusion Services and Immunohematology, G. R. Doshi and K. M. Mehta \\ Institute of Kidney Diseases \& Research Centre (IKDRC)-Dr. H. L. Trivedi Institute of Transplantation Sciences (ITS), Civil Hospi- \\ tal Campus, Ahmedabad, India.

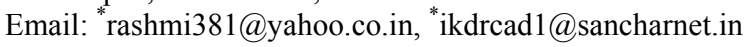

Received April $2^{\text {nd }}, 2012$, revised July $3^{\text {rd }}, 2012$, accepted July $21^{\text {st }}, 2012$

\begin{abstract}
Primary adrenal tumors are less commonly encountered in clinic. They may be functional/non-functional and noted incidentally when investigating for other problems. However there is no study available in Asian countries, and especially India regarding the incidence and natural history of these tumors. We carried out a study on adrenal tumors noted in our set-up for last five years to document the prevalence of adrenal tumors, their presentation along with the most common tumor followed by incidence of other tumors and their clinical and pathological presentation. This was a retrospective study in our hospital from June 2006 to 2011. 29 adrenalectomies performed over 5 years. Their clinical presentation and investigations were recorded and analyzed. Adrenal tumors accounted for $0.6 \%$ of total surgical specimens, 18 out of 29 belonged to males. Majority (85.2\%) of the patients were adults with mean age, 39.8 years. Majority (79.3\%) had presented with symptoms, incidentalomas were found in $20.7 \%$ patients out of which 2 belonged to potential kidney donors. Nonfunctioning tumors were noted in $58.6 \%$ patients. Pheochromocytoma was the commonest tumor noted in $68.9 \%$ followed by adrenal cortical adenoma in $13.7 \%$, carcinoma in $6.9 \%$ and lipoma, myelolipoma and ganglioneuroma, $3.45 \%$ each. All the patients are doing well over a mean follow-up of 2.5 years. To our knowledge this is the first study on incidence and natural history of primary adrenal tumors which are less commonly encountered and usually have good prognosis.
\end{abstract}

Keywords: Adrenal Tumors; Pheochromocytoma; Hypertension; Incidentaloma

\section{Introduction}

Primary adrenal tumors encountered in clinical practice are functioning/nonfunctioning tumors. Asymptomatic adrenal masses discovered incidentally (incidentalomas) are becoming increasingly frequent with availability of advanced imaging modalities like Computed Tomography (CT) Scan/magnetic resonance imaging (MRI). These techniques can now define adrenal masses as small as 0.5 $\mathrm{cm}$ in size and prevalence is up to $4 \%$ of abdominal studies [1-3]. Adrenal tumors are surgically removed due to the fear of malignant changes/hormonal disturbances created by them. Histopathology still remains the gold standard in their diagnosis. No statistical data about incidence of adrenal tumors, especially in India are available. We present 5 years single centre experience of adrenal tumors received in our surgical pathology section.

\section{Material and Methods}

Totally 29 adrenalectomies were received between Janu-

"Corresponding author. ary 2006 to December 2010 and analyzed histopathologically. Their case records were studied for clinical presentation and correlation with radiological [Ultrasonography (USG) CT, MRI] and pathological investigations. Functional status was evaluated by baseline hormonal assessment which included serum potassium, cortisol, aldosterone, urinary Vanillyl mandelic acid (VMA) and metanephrine levels.

All tumors were subjected to gross pathology, light microscopy and immunohistochemistry (IHC) evaluation.

\section{Results}

Adrenal tumors accounted for $0.6 \%$ of total surgical specimens. Out of 29 specimens 18 belonged to males. Majority $(85.2 \%)$ of the patients were adults $(n=25)$ with mean age, $39.8 \pm 10.2$ years (range: $21-58$ years) and 4 were children with mean age, $10.1 \pm 6.3$ years (range: 9 months to 14 years). Majority $(79.3 \%, \mathrm{n}=23$ ) of the patients had presented with symptoms; incidentalomas were found in $20.7 \%(\mathrm{n}=6)$ patients. Two out of 6 
incidentalomas belonged to potential kidney donors. Nonfunctioning tumors were noted in $58.6 \%(\mathrm{n}=17)$ patients (Table 1).

\subsection{Pathological Evaluation}

Adrenal cortical tumors were more common than medullary tumors accounting for $89.5 \%$ cases. Pheochromocytoma was the commonest adrenal tumor noted in $68.9 \%(\mathrm{n}=20)$ followed by adrenal cortical adenoma in $13.7 \%(\mathrm{n}=4)$, carcinoma in $6.9 \%(\mathrm{n}=2)$ and lipoma, myelolipoma and ganglioneuroma, $3.45 \%(\mathrm{n}=1)$ each.

\subsubsection{Pheochromocytoma}

The mean age was $35.7 \pm 14.2$ years with male predilection, affecting 14 males. Both sides were equally affected and all were unilateral. Hypertension was observed in $70 \%(n=14)$ patients who were on three anti-hypertensives before surgery. Elevated urinary VMA was noted in $55 \%(\mathrm{n}=11)$ with mean values, $14.3 \pm 3.4 \mathrm{mg} / 24$ hours (reference range: $2-8 \mathrm{mg} / 24 \mathrm{hr}$ ). Urinary metanephrin was elevated in $35 \%(\mathrm{n}=7)$ with mean value of $1.65 \pm$ $0.29 \mathrm{mg} / 24$ hours (reference range: $0-0.9 \mathrm{mg} / 24$ hours). Urinary cortisol was elevated in $36.4 \%(\mathrm{n}=4)$ patients with mean value of $240 \pm 42.43 \mathrm{microgram} / 24$ hours (reference range: 60 - 160 microgram/24hours). All of them showed gradual decrease in need of anti-hypertensives which were stopped after $6-8$ months of surgery. All patients are doing well without any anti-hypertensives over a mean follow-up of $2.53 \pm 1.42$ years. Their urinary hormonal levels also returned to normal range 3 weeks after surgery.

Gross and Histopathology:

The tumors were soft to firm in consistency with mean weight $99.7 \pm 100$ grams, size $7.14 \pm 2 \mathrm{~cm}$, well circumscribed with variegated appearance, yellow brown colored and showing rare areas of hemorrhage and necrosis (Figure 1(a)).

Histopathology revealed tumor cells arranged in organoid pattern or fascicles showing extensive areas of
"Zell ballen" appearance. Individual tumor cells were large, polygonal with mild atypia having fine granular eosinophilic cytoplasm and centrally placed large nuclei with prominent nucleoli (Figure 2(a)). Haemorrhage and necrosis were noted in variable amounts. The tumor was well circumscribed and surrounded by thick fibrous capsule in all cases. Atypical mitotic figures were noted in $85.7 \%(\mathrm{n}=18)$ and bizarre giant cells in $66.6 \%(\mathrm{n}=14)$ tumors. They were all exhibiting positivity to chromogranin and synaptophysin. However none showed features of malignancy in the form of capsular invasion or distant metastasis.

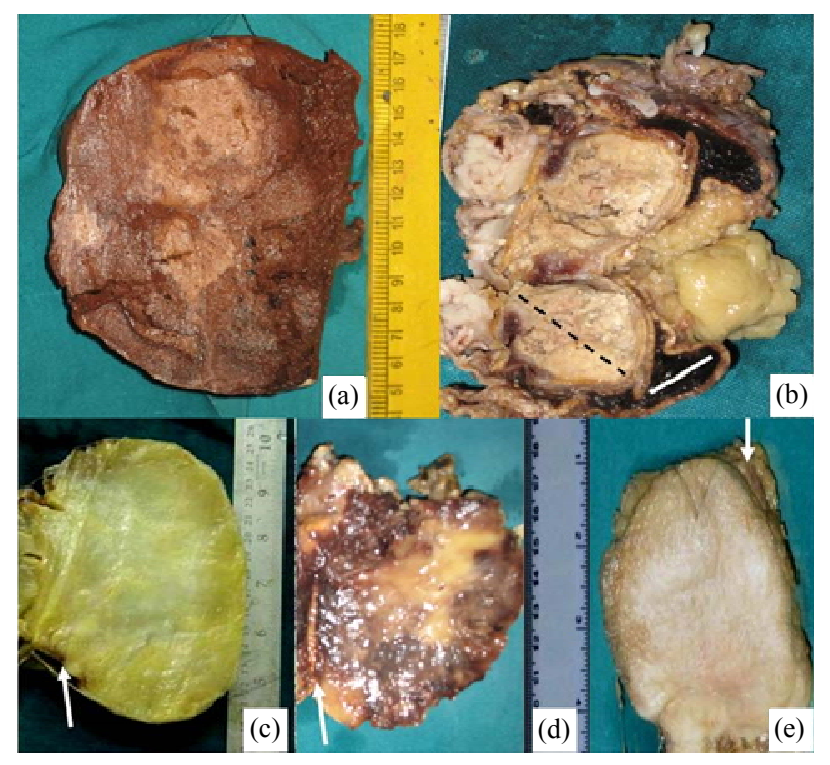

Figure 1. Gross appearance (cut surface) of adrenal tumors. (a) Pheochromocytoma with golden brown appearance; (b) Cortical Carcinoma: Nodular grey-white-black dashed line denoting tumor, white line denoting hemorrhagic area of adrenal gland; (c) Lipoma: Homogenous yellow fatty with myxomatous jellylike appearance; arrow depicting adrenal gland in periphery; (d) Myelolipoma: Variegated with hemorrhagic and yellowish fatty areas; arrow depicting adrenal gland in periphery; (e) Ganglioneuroma: Homogenous grey-white appearance.

Table 1. Demographics of adrenal tumors.

\begin{tabular}{|c|c|c|c|c|c|c|c|c|c|}
\hline Lesion & Number & $\begin{array}{l}\text { Mean (SD) age } \\
\text { (years) (range) }\end{array}$ & $\begin{array}{c}\text { Gender } \\
\text { M:F }\end{array}$ & HT/DM & F/NF & $\begin{array}{l}\text { Mean(SD) size } \\
\text { (cm) (range) }\end{array}$ & $\begin{array}{c}\text { Mean (SD) weight } \\
\text { (gm) (range) }\end{array}$ & Incidental & $\begin{array}{c}\text { Mean (SD) follow up } \\
\text { (years ) (range) }\end{array}$ \\
\hline Pheochromocytoma & 20 & $\begin{array}{c}35.7(14.2) \\
(12-58)\end{array}$ & $14: 6$ & $\begin{array}{l}\text { HT-15 } \\
\text { DM-2 }\end{array}$ & $8 / 12$ & $\begin{array}{c}7.14(2.21) \\
(4-13)\end{array}$ & $\begin{array}{c}99.75(100.16) \\
(10-400)\end{array}$ & 1 & $\begin{array}{c}2.53(1.42) \\
(0.78-5.52)\end{array}$ \\
\hline Adrenal adenoma & 4 & $\begin{array}{c}37.5(8.66) \\
(30-45)\end{array}$ & $1: 3$ & - & $1 / 3$ & $\begin{array}{c}5.17(0.85) \\
(4-6)\end{array}$ & $\begin{array}{c}35.4(26.2) \\
(15-60)\end{array}$ & 2 & $\begin{array}{c}2.84(1.76) \\
(1.35-5.02)\end{array}$ \\
\hline $\begin{array}{l}\text { Adrenal cortical } \\
\text { carcinoma }\end{array}$ & 2 & $\begin{array}{l}22.9(31.3) \\
(0.75-45)\end{array}$ & $1: 1$ & - & $1 / 1$ & $\begin{array}{l}8(2.83) \\
(6-10)\end{array}$ & $\begin{array}{c}145(77.78) \\
(90-200)\end{array}$ & 1 & $\begin{array}{c}0.95(0.24) \\
(0.78-1.12)\end{array}$ \\
\hline Lipoma & 1 & 43 & $1: 0$ & HT & $0 / 1$ & 15 & 810 & 1 & 2.73 \\
\hline Myelolipoma & 1 & 46 & $0: 1$ & HT & $1 / 0$ & 10 & 315 & - & 0.98 \\
\hline Ganglioneuroma & 1 & 33 & $1: 0$ & HT & $0 / 1$ & 10 & 300 & 1 & 0.82 \\
\hline
\end{tabular}

HT-Hypertension, DM-Diabetes Mellitus, F/NF-Functional/Non Functional. 


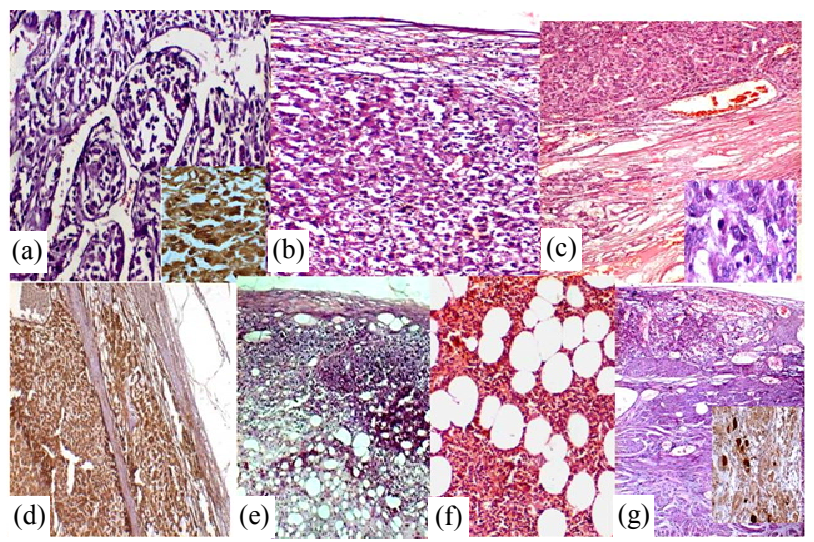

Figure 2. Adrenal tumor photomicrographs (H \& E stain, $\times 100$ ). (a) Pheochromocytoma: Tumor cells in "Zell-ballen" pattern, inset: cytoplasmic positivity with chromogranin; (b) Cortical Adenoma: Appearing mixture of zona glomerulosa and fasciculate; (c) Cortical Carcinoma: Diffuse sheets of large polygonal cells; inset $(\times 200)$ : showing mitotic activity; (d) Cortical Carcinoma: Vimentin positivity with capsular invasion; (e) Lipoma: Well-encapsulated mature adipose tissue tumor with adjacent normal parenchyma; (f) Myelolipoma: Proliferating mature adipose tissue with haematopoietic elements; (g) Ganglioneuroma: Mature ganglion and Schwann-like cells arranged in fascicles; inset $(\times 200)$ NSE positive.

\subsubsection{Adrenal Cortical Adenoma}

The next common tumor found was adrenal cortical adenoma in 4 patients, 3 females and 1 male with mean age, $37.5 \pm 8.66$ years. One of them, a 30 years old female presented with Cushing's syndrome and others were nonfunctioning. One out of these was an incidentaloma noted in a 45 years old lady who was a potential kidney donor. Both sides were equally affected. The kidney donor was subjected to donor nephrectomy after tumor removal and all are doing well over a mean follow-up of $2.84 \pm 1.76$ years.

Gross and Histopathology:

The tumors were soft to firm in consistency with mean weight $35.4 \pm 26.2$ grams, size $5.17 \pm 0.85 \mathrm{~cm}$, wellencapsulated and grey brown colored. Small foci of hemorrhage were seen.

Histopathology revealed tumor cells appearing to be mixture of zona glomerulosa and fasciculata arranged in sheets or organoid pattern. The tumor was well encapsulated with areas of haemorrhage and necrosis and not infiltrating in to surrounding parenchyma. The adrenal parenchyma adjacent to tumor showed unremarkable morphology (Figure 2(b)). No atypia or mitotic activity was noted. They were negative for epithelial membrane antigen and positive for synaptophysin and vimentin.

\subsubsection{Adrenal Cortical Carcinoma}

We found 2 patients with adrenal cortical carcinoma, a 9 months old male baby with a functional tumor, $10 \mathrm{~cm}$ in size, weighing 200 grams. The child had virilizing effect with hormonal activity showing serum testosterone of $6.38 \mathrm{ng} / \mathrm{dL}$ (normal value: $0.03-0.68 \mathrm{ng} / \mathrm{mL}$ at $1-12$ years age) and urinary cortisol value of 14.75 microgram/ 24 hours (normal range: 4.3 - 17.6 microgram/24hours). Three months after surgery his hormone levels returned to normal with unremarkable sonography finding. The second patient was a 45 years old lady who was a potential kidney donor with $6 \mathrm{~cm}$ incidentally detected nonfunctioning tumor in right adrenal gland weighing 90 grams. She was rejected as potential donor and over a follow-up of 1 year she is asymptomatic.

\section{Gross and Histopathology:}

The tumors were firm, nodular in consistency weighing 200 and 90 gms respectively and measuring 10 and 6 cms respectively, well circumscribed and greyish white colored (Figure 1(b)). The tumor of the infant was very necrotic and friable.

Histopathology revealed diffuse sheets of tumor cells that were large, polygonal with moderate to marked atypia. Individual cells had fine granular eosinophilic cytoplasm and centrally placed large nuclei with prominent nucleoli. Extensive hemorrhage and necrosis were noted. Few dilated cystic spaces filled with RBCs were also seen with $\geq 5$ mitotic figures/high power field with atypical mitotic figures amongst them. The tumor was well circumscribed and surrounded by thick fibrous capsule. The adrenal parenchyma adjacent to tumor showed unremarkable morphology. The tumor in lady had prominent capsular invasion. Vimentin was strongly positive and low molecular weight keratin was negative in both (Figures 2(c) and (d)).

\subsubsection{Adrenal Lipoma}

A 43 years old male with hypertension and past history of myocardial infarction was found to have non-functional tumor $15 \mathrm{~cm}$ in size, weighing 810 grams (Figure 1(c)). On gross examination the external surface was smooth and grey-yellow colored, and the adjacent adrenal gland measuring $6 \times 1.5 \times 0.5 \mathrm{~cm}$ in size was unremarkable. The cut surface was homogenous, yellow and fatty with myxomatous areas with jelly-like appearance and soft to firm in consistency. Microscopy revealed a well-encapsulated tumor composed of mature adipose tissue with myxoid degenerative changes and normal adrenal parenchyma (Figure 2(e)). He is also doing well after 2.73 years of surgery.

\subsubsection{Adrenal Myelolipoma}

It was noted in 1 patient who was a 46 years old lady with functional tumor showing high urinary cortisol of 229.6 microgram $/ 24$ hours and normal urinary VMA. The tumor was weighing 315 grams, measuring $10 \times 9.6$ $\times 6 \mathrm{~cm}$ in size. Outer surface showed variegated ap- 
pearance, few hemorrhagic areas were seen along with yellowish fatty areas. Cut surface showed variegated appearance, hemorrhagic along with fatty area with adjacent uninvolved strip of adrenal gland (Figure 1(d)).

Histopathology showed proliferating mature adipose tissue with haematopoietic elements containing myelocytes and metamyelocytes and remaining part of adrenal gland showed focal hemorrhage (Figure 2(f)). She is doing well over a follow-up of $0.98 \mathrm{yr}$.

\subsubsection{Ganglioneuroma}

We found ganglioneuroma in a 33 years old male who presented with epigastric pain with cholelithiasis and incidentally was found to have adrenal mass during USG. The tumor was large, weighing 300 grams, measuring 10 $\times 9 \times 7 \mathrm{~cm}$ in size, nodular, irregular grey colored, congested and partially covered with fatty tissue. Cut section showed a well circumscribed tumor mass with homogenous grey-white appearance (Figure 1(e)). Microscopy examination revealed normal adrenal cortical and medullary tissue with adjacent well circumscribed benign tumor mass of mature ganglion cells and Schwann-like cells arranged in fascicles, staining strongly with neuron-specific enolase and s-100 proteins. No immature cells or malignancy was noted (Figure 2(g)). Over a follow-up of 0.82 years he is doing fine.

\section{Discussion}

Adrenal gland tumors require a multi-disciplinary approach. The incidence in India is not available; in US the incidence of adrenal mass is approximately 5\% [4]. The average age of a person diagnosed with an adrenal gland tumor is between 45 and 50; however, these tumors can occur at any age. More women than men tend to be diagnosed with adrenal gland tumors. Our study differs from this observation. We have seen adrenal tumors affecting little earlier at mean age of $39.8 \pm 10.2$ years and males are more often diagnosed to have this tumor. One of the reasons could be that ours being a male dominated society, women even if they are suffering may not have been reported since they do not come to the hospital for treatment. Our study shows that approximately $80 \%$ of adrenal tumors are detected due to symptoms related/ unrelated to tumors and $55 \%$ are usually functional.

The incidence of adrenal incidentaloma is about $20 \%$. $[2,3,5]$ The symptoms depend on functional status and what hormone is over-produced. Tumors arising from adrenal cortex are adrenal adenomas and carcinomas, whereas tumors of adrenal medulla are neuroblastoma, pheochromocytoma, genglioneuroblastoma and ganglioneuroma. Other tumors like lipoma, myelolipoma, adenomatoid tumor, benign mesenchymal tumors, sarcoma, malignant lymphoma and melanoma are very rare. Our study also matches with the observation of others re- garding tumor type, pheochromocytoma accounting for about $69 \%$ of all adrenal tumors followed by adenoma noted in approximately $11.5 \%$, carcinoma in $7.7 \%$ and others noted rarely. Both the clinical and biochemical features of pheochromoctyomas result largely from the over-production of catecholamine with over half of patients developing marked hypertension. They occur at all ages but are most common in forth through sixth decades of life [6]. In our study also we found that hypertension was the commonest symptom however we found wide age range of 12 to 58 years with younger mean age of $35.7 \pm 14.2$ years of our patients. Accompanying complaints of weight loss, headache and palpitations are fairly common presentation [6-8]. Malignant pheochromocytomas account for $10 \%-25 \%$ of cases and are characterized by bone, lung, liver or splenic metastasis. Recently gene expression analysis raised the possibility that molecular markers might predict clinical tumor behavior [8]. We have not come across any malignant phaeochromocytoma in our study. Adrenal adenoma, a benign lesion usually affects women, which has also been our observation showing all females with this tumor with age range of 30 - 45 years. Adrenal cortical carcinoma is rare, highly aggressive tumor, incidence ranging for 0.5 to 12 per million ( 0.6 to 2 per million). It accounts for $0.05 \%$ to $2 \%$ of all malignancies. There is bimodal age distribution with peak incidence in the first and fifth decades of the life. The gender distribution amongst patients with adrenal carcinoma appears to vary in different series, still females are commonly affected $[3,9,10]$. Virilization by androgen secreting tumors is common phenomenon in children, its rate is much lower in adults [11-13]. In children it has less aggressive clinical course and responds better with surgery and other therapeutic modalities as compared to adults. Both our patients are doing well over a follow up of 1 year approximately, unlike other studies showing a median survival of 18 months after diagnosis $[9,12]$.

Adrenal lipomatous tumors are uncommon, accounting for $4.8 \%$ of the primary adrenal tumors noted in the 30 years period [14-16]. Most of these tumors are asymptomatic and found incidentally. Theories of pathogenesis include metaplastic origin, retention of embryonic rests or extramedullary origin. Myelolipoma accounts for 2.6 to $15 \%$ of primary adrenal tumor, usually noted in adults with age range of $41-84$ years [17-19]. Ganglioneuroma is a rare benign tumor of adrenal gland arising from neural crest cells. GN is common in children and in sympathetic nervous system, posterior mediastinum and retroperitoneum, very rare in adults and in adrenal gland with equal gender distribution. A preference of thoracic (41.5\%) followed by abdominal-non-adrenal (37.5\%) and adrenal GN (21\%) as been observed in one series. Most of the GN are non-functioning, asymptomatic, incidenttally detected by imaging procedures as in our study also. 
However a patient may have abdominal pain, gastroenteritis, weight loss, hypertension and diarrhea. Histologically two benign subtype of GN- mature and maturing have been noted malignant transformation has also been reported [20-23].

To our knowledge this is the first Indian study on natural history of adrenal tumors. Although not so common, they are encountered in routine practice, overall they are amenable to surgical modalities and have good prognosis. Pheochromocytomas are the commonest adrenal tumors in our set-up. Larger studies are required to find the incidence in our part of the world.

\section{Acknowledgements}

Treating clinicians: Pranjal R. Modi and S. J. Rizvi, Professors in Urology and Transplantation, Veena R. Shah: Prof. \& HOD, Anesthesia and Critical Care, Hargovind L. Trivedi: Department of Nephrology \& Transplantation Medicine, Jyotsana Suthar: Librarian who helped in literature search.

\section{REFERENCES}

[1] S. Bovio, A. Cataldi, G. Reimondo, et al., "Prevalence of Adrenal Incidentaloma in a Contemporary Computerized Tomography Series," Journal of Endocrinological Investigation, Vol. 29, No. 4, 2006, pp. 298-302.

[2] P. K. Singh and H. N. Buch, "Adrenal Incidentaloma: Evaluation and Management," Journal of Clinical Pathology, Vol. 61, No. 11, 2008, pp. 1168-1173. doi:10.1136/jcp.2006.044313

[3] T. Gopan, E. Remer and A. H. Hamrahian, "Evaluating and Managing Adrenal Incidentalomas," Cleveland Clinic Journal of Medicine, Vol. 73, No. 6, 2006, pp. 561-568. doi:10.3949/ccjm.73.6.561

[4] J. H. Song, F. S. Chaudhry and W. W. Mayo-Smith, "The Incidental Adrenal Mass on CT: Prevalence of Adrenal Disease in 1049 Consecutive Adrenal Masses in Patients with No Known Malignancy," American Journal of Roentgenology, Vol. 190, No. 5, 2008, pp. 1163-1168. doi:10.2214/AJR.07.2799

[5] L. K. Nieman, "Approach to the Patient with and Adrenal Incidentaloma," The Journal of Clinical Endocrinology \& Metabolism, Vol. 95, No. 9, 2010, pp. 4106-4113. doi:10.1210/jc.2010-0457

[6] M. M. Walther, H. R. Keiser and W. M. Linehan, "Pheochromocytoma: Evaluation, Diagnosis, and Treatment," World Journal of Urology, Vol. 17, No. 1, 1999, pp. 3539. doi:10.1007/s003450050102

[7] J. A. Virseda Rodríguez, J. Martínez Ruiz, P. Carrión López, et al., "Pheochromocytoma: More than a Decade of Experience. Review of the Literature," Actas Urológicas Españolas, Vol. 34, No. 10, 2010, pp. 888-892. doi:10.4321/S0210-48062010001000013

[8] Y. Alderazi, M. W. Yeh, B. G. Robinson, et al., "Phaeochromocytoma: Current Concepts," Medical Journal of
Australia, Vol. 183, No. 4, 2005, pp. 201-204.

[9] B. L. Wajchenberg, M. A. Albergaria Pereira, B. B. Medonca, et al., "Adrenocortical Carcinoma, Clinical and Laboratory Observations," Cancer, Vol. 88, No. 4, 2000, pp. 711-736. doi:10.1002/(SICI)1097-0142(20000215)88:4<711::AIDCNCR1>3.3.CO;2-N

[10] G. Mansmann, J. Lau, E. Balk, et al., "The Clinically Inapparent Adrenal Mass: Update in Diagnosis and Management," Endocrine Reviews, Vol. 25, No. 2, 2004, pp. 309-340. doi:10.1210/er.2002-0031

[11] S. Kumar, P. Tiwari, R. K. Das, et al., "Virilizing Adrenal Carcinoma in a 3-Year Old Boy: A Rarity," Indian Journal of Medical and Paediatric Oncology, Vol. 31, No. 1, 2010, pp. 30-32.

[12] A. A. Ahmed, "Adrenocorical Neoplasms in Young Children: Age as a Prognostic Factor," Annals of Clinical \& Laboratory Science, Vol. 39, No. 3, 2009, pp. 277-282.

[13] S. B. Bavdekar, R. R. Kasla, R. C. Parmar and G. S. Hathi, "Selective Testosterone Secreting Adenocrotical Carcinoma in an Infant," Indian Journal of Pediatrics, Vol. 68, No. 1, 2001, pp. 95-97. doi:10.1007/BF02728872

[14] R. D. Patel, A. V. Vanikar and P. R. Modi, "Giant Lipoma of the Adrenal Gland: A Case Report," Journal of Medical Case Reports, Vol. 5, No. 1, 2011, p. 78. doi:10.1186/1752-1947-5-78

[15] K. Y. Lam and C. Y. Lo, "Adrenal Lipomatous Tumours: A 30 Year Clinicopathological Experience at a Single Institution," Journal of Clinical Pathology, Vol. 54, No. 9 , 2001, pp. 707-712. doi:10.1136/jcp.54.9.707

[16] K. N. Milathianakis, C. D. Farfarelos, I. M. Mpogdanos and D. K. Karamanolakis, "Giant Lipoma of the Adrenal Gland," Journal of Urology, Vol. 167, No. 4, 2002, p. 1777. doi:10.1016/S0022-5347(05)65198-1

[17] R. T. Kloos, et al., "Incidentally Discovered Adrenal Masses," Endocrine Reviews, Vol. 16, No. 4, 1995, pp. 460-484.

[18] V. G. Patel, O. A. Babalola, J. K. Fortson and W. L. Weaver, "Adrenal Myelolipoma: Report of a Case and Review of Literature," The American Journal of Surgery, Vol. 72, No. 7, 2006, pp. 649-654.

[19] G. C. Fernandes, R. K. Gupta and B. M. Kandalkar, "Giant Adrenal Myelolipoma," Indian Journal of Pathology and Microbiology, Vol. 53, No. 2, 2010, pp. 325-326. doi:10.4103/0377-4929.64314

[20] T. Yoshida, J. Saito, T. Takao, et al., "Adrenal Ganglioneuroma: A Case Report," Hinyokika Kiyo, Vol. 51, No. 2, 2005, pp. 93-96.

[21] Y. Qing, et al., "Adrenal Ganglioneuromas: A 10 Year Experience in a Chinese Population," Surgery, Vol. 147, No. 6, 2010, pp. 854-860. doi:10.1016/j.surg.2009.11.010

[22] C. Erem, et al., "Adrenal Ganglioneuroma: Report of a New Case," Endocrinology, Vol. 35, No. 3, 2009, pp. 293-296.

[23] B. Geoerger, et al., "Metabolic Activity and Clinical Features of Primary Ganglioneuromas," Cancer, Vol. 91, No. 
10, 2001, pp. 1905-1913.

doi:10.1002/1097-0142(20010515)91:10<1905::AID-CN
$\underline{\mathrm{CR} 1213>3.0 . \mathrm{CO} ; 2-4}$

MRI: Magnetic resonance imaging

NSE: Neuron specific enolase

USG: Ultrasonography

VMA: Vanillyl mandelic acid

\section{Abbreviations}

CT: Computed tomography GN: Ganglioneuroma

IHC: Immunohistochemistry 